\title{
Primeira Parte
}

\section{EXPERIÊNCIAS TEÓRICAS EM LINGUÍSTICA}





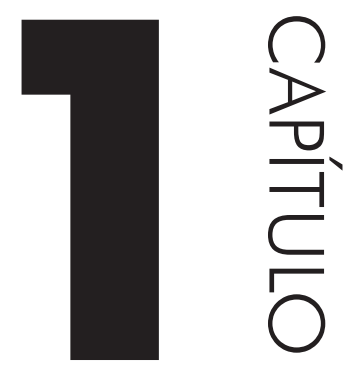

\section{CONTRIBUICÕ̃ES DE LUIZ ANTÔNIO MARCUSCHI PARA A LINGUISTIICA BRASILEIRA \\ DO MICROCOSMO CONVERSACIONAL PARA A FORMULAÇÃO DOS PRINCÍPIOS LINGUISTIICOS}

Ataliba Teixeira de Castilho

\section{APRESENTAÇ̃̃O}

É uma grande honra abrir este evento rememorando as contribuições de Luiz Antonio Marcuschi para a Linguística brasileira, tanto quanto os desdobramentos dessas contribuições. Agradeço à Profa. Valéria Gomes, Presidente do Grupo de Estudos Linguísticos do Nordeste, pela oportunidade desta participação.

Marcuschi se graduou em Filosofia pela Pontifícia Universidade Católica do Rio Grande do Sul, em 1968. Doutorou-se em Letras pela Universita et Erlangen-Nurnberg (Friedrich-Alexander), com um trabalho sobre Wittgenstein, em 1976. Desenvolveu pesquisas de pós-doutorado na Universität Freiburg, em 1988. 
De volta ao Brasil, passou a lecionar Linguística na Universidade Federal de Pernambuco, desde 1976, da qual se tornou Professor Titular em 1992. Entre 1983 e 1985, dirigiu a Editora Massangana, da Fundação Joaquim Nabuco.

Atuou nas áreas de Filosofia da Linguagem, Metodologia, Epistemologia, e Lógica, desenvolvendo pesquisas nas seguintes linhas: Descrição da língua falada e da língua escrita, Compreensão textual na fala e na escrita, Organização da interação verbal, Oralidade e ensino de língua, Análise de gêneros textuais.

Publicou livros de grande circulação no país, influenciando positivamente as novas gerações de linguistas brasileiros:

- Linguagem e classes sociais (1975).

- Linguística de texto: o que é e como se faz (1983).

- Análise da conversação (1986).

- Quem é quem na pesquisa em letras e linguística no Brasil (1992).

- A repetição na língua falada: formas e funções (1992).

- Da fala para a escrita: atividades de retextualização (2001).

Além desses livros, primorosamente reeditados pela Editora Universitária da UFPE em 2009, Marcuschi publicou 47 artigos em revistas científicas, 48 capítulos de livros, orientou 50 dissertações de mestrado e 15 teses de doutorado - tudo isso em meio a uma intensíssima participação em congressos, encontros científicos e órgãos de representação dos linguistas, tais como a Anpoll, o CNPq e a Capes.

Ele nos deixou muito cedo, mas, tendo trabalhado com grande vigor, assinalou fortemente sua passagem pela Linguística brasileira, em que introduziu pesquisas em Pragmática da linguagem, particularmente na Análise da conversação e na Linguística do texto.

Nesta fala, mostrarei os desdobramentos de seus trabalhos sobre a conversação e o texto, desenvolvidos no Projeto Nurc e no Projeto de Gramática do Português Falado, focalizando as generalizações que vêm sendo construídas a partir de suas pesquisas nessas áreas.

O texto se compõe de quatro seções: (1) a interação conversacional, (2) marcas da interação na construção da sentença e do texto, (3) as estratégias conversacionais e os processos de construção linguística, (4) do microcosmo conversacional à formulação de princípios linguísticos.

Articulei este texto caminhando das manifestações linguísticas mais concretas para suas propriedades mais abstratas, reproduzindo em parte o percurso científico do nosso homenageado.

Oxalá ele tivesse tido tempo para promover ele mesmo as generalizações derivadas das modernas pesquisas brasileiras sobre a pragmática da língua fala- 
da! Presto uma homenagem à sua memória, pois desde 1998 tenho procurado preencher essa lacuna.

\section{A INTERAÇÃO CONVERSACIONAL}

Começo com um pouco de história.

Ali pelos anos 1980, estavam em curso as atividades do Projeto NURC. A equipe de São Paulo tinha feito as gravações e começara a publicar amostras de transcrições.

Aplicando a esses materiais o Guia questionário que deveria orientar as descrições, descobrimos que não chegaríamos a lugar nenhum, por razões que expus em outra ocasião: Castilho (1984 a). Vai daí, aproveitando um dos seminários do Grupo de Estudos Linguísticos do Estado de São Paulo, que se reunia em Campinas, o Marcuschi, o Preti e eu mesmo chamamos para uma conversa o Marcelo Dascal, que pesquisava e lecionava na Unicamp. Dascal atuava na enorme seara da Pragmática, e certamente poderia nos ajudar.

Pois o Dascal mandou tocar uma das fitas, e passados alguns minutos exclamou que havia uma enormidade de fenômenos a estudar ali! Demonstrou sua afirmação com análises sobre a administração dos turnos, abrindo uma perspectiva na qual eu nunca tinha pensado.

Daqui resultaram as primeiras pesquisas sobre a conversação, cujo primeiro produto foi a Análise da conversação, livro que Marcuschi publicou em 1986.

Foi enorme a repercussão desse trabalho, que desencadeou uma grande variedade de estudos pragmáticos da conversação.

Vejamos o que se aprende estudando essas pesquisas.

A conversação é uma atividade linguística básica. Ela integra as práticas diárias de qualquer cidadão, independentemente de seu nível sociocultural.

Numa conversação, dois ou mais participantes se alternam, discorrendo livremente sobre tópicos propiciados pela vida diária, "fora dos ambientes institucionais como o serviço religioso, as audiências de um tribunal, as salas de aula etc.”, como reconhece Levinson (1983:284).

Autor do primeiro livro em língua portuguesa sobre o assunto, Luiz Antonio Marcuschi acrescenta que "a conversação é a primeira das formas da linguagem a que estamos expostos e provavelmente a única da qual nunca abdicamos pela vida afora": Marcuschi (1986:14).

Uma condição fundamental para que duas ou mais pessoas se engajem numa conversação é que "cada participante reconheça um propósito comum ou um conjunto de propósitos, uma direção mutuamente aceita” (Grice (1967) 1982:86). 
Vejamos o que se aprende neste recorte de entrevista, em que o Loc. 1, engenheiro, paulistano, 26 anos, conversa com o Loc. 2, psicóloga, paulistana, 23 anos, sobre andar por São Paulo. A transcrição segue os princípios adotados pelo Projeto NURC, de onde procede essa entrevista como se sabe, os diferentes tipos de transcrição constituem a língua falada como objeto de estudos.

Exemplo (1) Projeto Nurc/São Paulo D2 343

1. Loc. 1 - tem saído ultimamente... de carro?

2. Loc. 2 - tenho... mas você diz sair... fora... sair normalmente para a escola... essas coisas?

3. Loc. 1 - pegar a cidade...

4. Loc. 2 - tenho saído sim... assim em termos mas eu acho por exemplo:.... de sair:....éh:.... sabe sair por aí::descobrir

1

5. Loc. 1 - uhn

6. Loc. 2 - lugares novos e tal acho que meu conhecimento de São Paulo é muito restrito se comparar com papai por exemplo...

7. Loc. 1 - eu fui::... quinta-feira... não... foi terça-feira à noite fui lá no () née lá na Celso Furtado

8. Loc. 2 - éh::

9. Loc. 1 - passei ali em frente à::Faculdade de Direito... então estava lembrando... que ei ia muito lá quando tinha sete nove anos... (com) a titia sabe? e.:... está muito pior a cidade... está... o aspecto dos prédios assim é bem mais sujo... tudo acinzentado né?

10. Loc 2 - uhn... polvição né?

Numa conversação, os falantes se alternam em turnos. O turno conversacional é cada segmento produzido por um falante. Houve 10 turnos na transcrição acima. Por essa definição, qualquer emissão de voz é um turno, como em (5) $u h n$, e em (8) éh::::

Sacks, Schegloff e Jefferson ((1974) 2003:38) identificaram as regras de alternância dos turnos. Quando conversamos, prevemos o momento de nossa entrada na corrente conversacional, pois dispomos de uma "habilidade de projetar o final de um turno e decidir sobre o momento de entrada na corrente da fala".

Ainda segundo esses autores, a conversação encerra dois componentes, a construção dos turnos e a alocação dos turnos, ambas sujeitas ao princípio de projeção interacional.

Simplificando bastante as coisas, pode-se reconhecer que as seguintes estratégias assinalam a administração dos turnos: (i) manutenção do turno, (ii) assalto ao turno, (iii) passagem consentida do turno, (iv) sistema de correções, (v) marcação conversacional. Vejamos por alto cada uma dessas estratégias, detalhada em Marcuschi (1986) e Castilho (1998a). 
(1) Manutenção do turno: para assegurar nosso direito à voz, evitamos as pausas longas, preenchemos o silêncio alongando vogais e consoantes finais, corrigimos alguma coisa que tenhamos dito, repelimos ou incorporamos a correção do interlocutor. No exemplo (1), o alongamento de vogais e de consoantes finais é assinalado por dois pontos contíguos, o que ocorreu nos turnos (4), (7) e (9). Essas são as estratégias do locutor, ou seja, do falante com direito à voz.

(2) Assalto ao turno: para entrar na corrente da fala, assaltamos o turno, (i) interrompendo o locutor, (ii) corrigindo-o, numa manobra que ocasiona uma superposição de vozes, como entre (4) e (5), (iii) oferecendo nossa colaboração no desenvolvimento do tema, aproveitando alguma pausa longa que tenha sido produzida pelo interlocutor para entrar na conversação, como nos turnos (3) e (10); essas colaborações são manobras nada inocentes. Essas são as estratégias do interlocutor, que busca para si o direito à voz.

(3) Passagem consentida do turno: esta é uma entrada não conflitiva na corrente da fala. O locutor pode nos passar a palavra, através do olhar ou de expressões tais como "e você, o que pensa disso?" O exemplo (1) não traz exemplos dessa estratégia.

(4) Sistema de correções: quando falamos, frequentemente voltamos atrás para corrigir o que foi dito, pois na língua falada coexistem o planejamento e a execução. Corrigimos erros de planejamento, ou seja, corrigimos o rumo da conversação. O sistema de correção é na verdade um alimentador da conversação. Correção, aqui, nada tem a ver com adequação à norma culta.

A correção discursiva não é um exercício desinteressado. Ela pode partir do locutor (= autocorreção) ou do interlocutor (= heterocorreção). No primeiro caso, corrigimos alguma estratégia discursiva para abortar o assalto ao nosso turno, prevendo que se armava uma intervenção. No segundo caso, estamos declaradamente assaltando o turno.

Também promovemos correções discursivas, (i) truncando uma palavra que consideramos inadequada, substituindo-a por outra, (ii) negando a palavra já pronunciada por inteiro e substituindo-a por outra, como em (7), (iii) parafraseando sintagmas e sentenças, procurando identificar a expressão mais adequada à situação de fala.

O sistema de correção evidencia que estamos monitorando o diálogo o tempo todo. Não é correto, portanto, admitir que a linguagem humana se desenvolve automaticamente, quase que sem pensar.

Os turnos podem ser discursivamente independentes ou dependentes entre si, evidenciando neste caso algum tipo de vínculo pragmático. A dependência entre turnos forma os pares adjacentes, outra categoria identificada pelos analistas da conversação.

Ocorrem pares adjacentes nas situações de (i) pergunta-resposta, como em (1) e (2), (ii) saudação-saudação, (iii) reclamação-pedido de desculpas, (iv) advertência-aceitação ou recusa da advertência. Quando o primeiro termo desses pares é formulado, espera-se que ocorra o segundo termo. 
Os pares adjacentes estão para o Discurso, assim como a relação de dependência sintática está para a Sintaxe, exemplificando um caso de harmonia intersistêmica. A harmonia intersistêmica (também denominada harmonia transcategorial) aponta para a independência ente os sistemas do Léxico, Semântica, Discurso e Gramática.com isto, não estou afirmando que os pares adjacentes são causas da subordinação sentencial, que seriam sua consequência. Nem o contrário disso, pois não lidamos aqui com regras de determinação.

Analistas da conversação observaram que às vezes não ocorre o turno esperado. É esse o caso de um convite não aceito, ou de uma pergunta a que se responde com outra pergunta, e assim por diante. A violação do comportamento linguístico esperado foi denominada despreferência por Marcuschi (1986).

(5) Os marcadores discursivos constituem outra propriedade da conversação. Essas expressões foram bastante estudadas no Brasil, entre 1980 e 1990. Anteriormente aos estudos da língua falada, Manuel Said Ali Ida (apud Urbano, 1993) foi entre nós o primeiro a analisar e a classificar os marcadores no PB, distinguindo os marcadores linguísticos (verbais e prosódicos) dos marcadores não linguísticos (olhar, riso, expressão corporal).

Considerando as funções e o lugar de colocação dos marcadores no enunciado, podemos organizar o seguinte quadro:

Quadro 1 - Marcadores discursivos no PB

\begin{tabular}{|c|c|}
\hline $\begin{array}{c}\text { MARCADORES INTERPESSOAIS } \\
\text { (= orientados para o interlocutor) }\end{array}$ & $\begin{array}{l}\text { MARCADORES IDEACIONAIS } \\
\text { (= orientados para o texto) }\end{array}$ \\
\hline $\begin{array}{c}\text { Iniciais: } \\
\text { ah ... eh ... ahn ... } \\
\text { olha ... } \\
\text { e aí, tudo bem? } \\
\text { tudo em cima/riba? } \\
\text { escuta ... vem cá ... } \\
\text { como você sabe ... } \\
\text { mas ... }\end{array}$ & $\begin{array}{c}\text { Iniciam o tópico: } \\
\text { bom ... } \\
\text { bem ... } \\
\text { assim ... } \\
\text { seguinte ... } \\
\text { por exemplo ... } \\
\text { e por falar em ... } \\
\text { quanto a ... } \\
\text { você já ouviu a última? }\end{array}$ \\
\hline $\begin{array}{c}\text { Mediais: } \\
\ldots \text { é ... } \\
\ldots \text { é claro ... } \\
\ldots \text { exato ... } \\
\ldots \text { tá ... } \\
\ldots \text { tô entendendo ... }\end{array}$ & $\begin{array}{c}\text { Recusam o tópico: } \\
\text { essa não! } \\
\text { peraí, sem essa! } \\
\text { corta essa! } \\
\text { xi::lá vem você de novo! }\end{array}$ \\
\hline
\end{tabular}




\begin{tabular}{|c|c|}
\hline \multirow{5}{*}{$\begin{array}{c}\text { Finais: } \\
\text {.. sabe? sabia? } \\
\text {... entende? } \\
\text {...compreende? } \\
\text {... não é mesmo? } \\
\text {... não ée né? } \\
\text {... tá? } \\
\text {... viu? } \\
\text {... pô! }\end{array}$} & $\begin{array}{c}\text { Aceitam o tópico: } \\
\text { tá bom ... } \\
\text { vamos lá ... } \\
\text { OK ... } \\
\text { fala ... }\end{array}$ \\
\hline & $\begin{array}{c}\text { Organizam o tópico: } \\
\text { inicialmente ... } \\
\text { primeiramente ... } \\
\text { em segundo lugar ... } \\
\text { em seguida ... } \\
\text { e então ... } \\
\text { e aí ... } \\
\text { agora ... } \\
\text { e depois ... } \\
\text { outra coisa ... } \\
\text { e tem mais ... }\end{array}$ \\
\hline & $\begin{array}{l}\text { Operam a mudança de tópico: } \\
\text { já (em a agricultura vai bem, a indústria } \\
\text { se expandiu, já a situação do emprego } \\
\text { não acompanhou esse progresso todo.) }\end{array}$ \\
\hline & $\begin{array}{c}\text { Modalizam o tópico: } \\
\text { sim, mas ... } \\
\text { pra mim ... } \\
\text { eu acho que ... } \\
\text { parece que ... } \\
\text { pode ser que ... } \\
\text { possivelmente ... } \\
\text { provavelmente ... } \\
\text { disque ... (= dizem que ...) } \\
\text { sei lá ... } \\
\text { não sei ... } \\
\text { de certa maneira ... } \\
\text { num certo sentido ... } \\
\text { basicamente ... }\end{array}$ \\
\hline & $\begin{array}{c}\text { Finalizam o tópico: } \\
\text { papapa ... } \\
\text { e coisa e tal ... } \\
\text { valeu ... } \\
\text { é isso aí ... } \\
\text { falô ... }\end{array}$ \\
\hline
\end{tabular}


Em suma, o planejamento e a execução linguística ocorrem simultaneamente na língua falada, o que aponta para outra característica das línguas naturais quando consideradas como sistemas complexos. Voltarei a esta questão na seção 3 deste texto.

\section{MARCAS DA INTERAÇÃOO NA CONSTRUC̦ÃO DA SENTENC̦A E DO TEXTO}

Pesquisas desenvolvidas pelo Projeto de Gramática do Português Falado no Brasil (1988-2006) comprovaram abundantemente a presença de marcas interacionais no processamento do texto e da sentença, mesmo na língua escrita.

Basta consultar a série de consolidação dos resultados desse projeto para comprovar essa afirmativa: Abaurre (Org.), 2013), Alves; Rodrigues (Org.), 2015), Ilari (Org.), 2014, 2015), Jubran (Org.), 2015), Kato; Nascimento (Org.), 2015), Neves (Org.), 2016).

Em Jubran (Org.), 2015), por exemplo, encontra-se uma teoria sobre a construção interacional do texto. Interpretando essa teoria, pode-se descrever o texto falado a partir das seguintes categorias processuais:

(1) Unidade tópica.

(2) Reformulação do quadro tópico: repetição, paráfrase.

(3) Descontinuação do quadro tópico: parentetização, digressão.

(4) Conexão textual.

Essas categorias foram descritas em Castilho (1998a, capítulo III, 2010 a, capítulo 2, seção 2. 3) e em Jubran (Org. (2006) 2015).

Pode-se propor uma análise sistemática da construção da sentença identificando os correlatos desses processos no interior dessa unidade gramatical.

\section{Unidade tópica}

Quando damos início a uma interação conversacional produzimos unidades tópicas, integradas na discursivização, de acordo com a concepção aqui adotada.

Defini a unidade tópica, ou unidade discursiva, na língua falada em Castilho (1987:253), como um segmento do texto caracterizado semanticamente por preservar a propriedade de coerência temática da unidade maior, atendo-se como arranjo temático secundário ao processo informativo de um subtema, e formalmente por se compor de um núcleo e de duas margens, sendo facultativo o preenchimento dessas margens.

O núcleo da unidade tópica se compõe de uma ou mais sentenças, tematicamente centradas. A margem esquerda é preenchida por marcadores discursivos 
orientados para a organização do texto, e a margem direita, por marcadores orientados para o interlocutor.

Transcrevendo textualmente o exemplo (1), citado acima, identificam-se as seguintes unidades tópicas, numeradas na primeira coluna:

Quadro 2 - Unidades tópicas exemplificadas no exemplo (1)

\begin{tabular}{|c|c|c|c|}
\hline $\begin{array}{l}\text { Unidade } \\
\text { tópica }\end{array}$ & $\begin{array}{l}\text { Marcador } \\
\text { discursivo } \\
\text { orientado } \\
\text { para o texto }\end{array}$ & $\begin{array}{l}\text { Sentenças e sintagmas } \\
\text { tematicamente centrados }\end{array}$ & $\begin{array}{l}\text { Marcador } \\
\text { discursivo } \\
\text { orientado } \\
\text { para o } \\
\text { interlocutor }\end{array}$ \\
\hline 1 & $\varnothing$ & $\begin{array}{l}\text { L1. tem saído ultimamente... de carro? } \\
\qquad \text { L2. tenho... } \\
\text { L3. mas você diz sair... fora... } \\
\text { sair normalmente para a escola... (a) }\end{array}$ & $\begin{array}{l}\text { (a) essas } \\
\text { coisas? }\end{array}$ \\
\hline 2 & $\varnothing$ & L1. pegar a cidade... & $\varnothing$ \\
\hline 3 & $\begin{array}{l}\text { (b) mas } \\
\text { (c) por } \\
\text { exemplo:: } \\
\text { (d) éh::... }\end{array}$ & $\begin{array}{l}\text { L2. tenho saído sim... assim em termos } \\
\qquad \begin{array}{l}\text { (b) eu acho (c) } \\
\text { de sair:.... (d) (e) } \\
\text { sair por aí:: } \\
\text { descobrir (f) }\end{array}\end{array}$ & $\begin{array}{l}\text { (e) sabe } \\
\text { (f) L1. uhn }\end{array}$ \\
\hline 4 & (g) e tal & lugares novos (g) & \\
\hline 5 & $\begin{array}{c}\text { (h) por } \\
\text { exemplo... }\end{array}$ & $\begin{array}{c}\text { acho que meu conhecimento de São } \\
\text { Paulo é muito restrito } \\
\text { se comparar com papai (h) }\end{array}$ & \\
\hline 6 & (i) éh & $\begin{array}{l}\text { L1. eu fui:.... quinta-feira... não... } \\
\text { foi terça-feira à noite } \\
\text { fui lá no ()lá (i) na Celso Furtado } \\
\text { L2. (i) }\end{array}$ & (i) né? \\
\hline 7 & $(k)$ então & $\begin{array}{l}\text { L1. passei ali em frente à::Faculdade } \\
\text { de Direito... } \\
\qquad(\mathrm{k}) \text { estava lembrando... } \\
\text { que ei ia muito lá } \\
\text { quando tinha sete nove anos... (com) } \\
\text { a titia e:.... (l) }\end{array}$ & (l) sabe? \\
\hline 8 & $\begin{array}{l}\text { (m) e:: } \ldots \\
\text { L2. uhn } \ldots\end{array}$ & $\begin{array}{c}\text { (m) está muito pior a cidade... está... } \\
\text { o aspecto dos prédios assim é bem } \\
\text { mais sujo... tudo acinzentado (n) } \\
\text { polvição (o) }\end{array}$ & $\begin{array}{l}\text { (n) né? } \\
\text { (o) né? }\end{array}$ \\
\hline
\end{tabular}


Nesse quadro, enumero na coluna 1 as unidades tópicas, transcrevo na coluna 2 os marcadores discursivos orientados para a organização do texto, na coluna 3 os sintagmas e sentenças tematicamente orientados, e na coluna 4 os marcadores orientados para o interlocutor. As letras entre parênteses indicam o lugar em que ocorreram os marcadores discursivos. As colunas 2 e 4 recolhem os constituintes periféricos da unidade tópica, por isso mesmo nem sempre realizados. A coluna 3 recolhe o núcleo da unidade tópica.

As unidades 1 a 4 são narrativas; elas constituem a figura do discurso, ocupada pelos personagens e eventos mais relevantes. As unidades 5 e 8 são dissertativas, e constituem o fundo do discurso, ocupado por comentários provocados pelos eventos da figura, ou por descrições do ambiente.

Há uma harmonia intersistêmica entre as categorias de figura e fundo do Discurso e a estrutura argumental (= figura) e a estrutura adjuncional (= fundo) da sentença, no sistema da Gramática.

Na língua escrita, o parágrafo é o correlato das unidades tópicas da oralidade.

\section{Reformulação do quadro tópico: repetição e paráfrase}

A reativação das categorias discursivas produz as reformulações no quadro tópico, instrumentada por repetições e paráfrases, que são estratégias conversacionais muito frequentes.

São muitas as estratégias de reformulação tópica, mas vamos focalizar aqui apenas duas: a repetição e a paráfrase.

Falando de um modo geral, repetir e parafrasear é fazer retornar à consideração algum tópico já versado anteriormente. $\mathrm{O}$ correlato dessa estratégia no sistema da Semântica é a foricidade. A repetição e a paráfrase se integram no processo discursivo básico de manutenção da interação.

Entende-se por repetição a recorrência de estruturas linguísticas, como os sintagmas nominais do exemplo (2), e as sentenças do exemplo (3). Marcando a primeira ocorrência com a letra $\mathrm{M}$, de matriz, e sua repetição com a letra $\mathrm{R}$, assim podem ser transcritas as repetições:

Exemplo (2) Repetição do sintagma nominal (Projeto NURC D2 POA 291)

\begin{tabular}{|c|c|c|}
\hline $\mathbf{M}$ & peixe & \\
\hline $\mathbf{R 1}$ & peixe & aqui no Rio Grande do Sul \\
\hline R2 eu tenho impressão que se come & peixe & $\begin{array}{c}\text { exclusivamente na Semana } \\
\text { Santa }\end{array}$ \\
\hline
\end{tabular}


Exemplo (3) Repetição de sentença (exemplo de Marcuschi, 2006b:246)

M1 a mercadoria mais cara no país inda é o dinheiro .. como é caro comprar dinheiro

$\mathbf{R} 1$ é o negócio mais caro inda é dinheiro

M2 porque o dinheiro é um elemento de troca, certo?

R2 o dinheiro é um elemento de troca

Comparando (2) a (3), vê-se que a repetição da sentença vem associada ao mecanismo de paráfrase, que será examinado a seguir. Assim, mercadoria em (2M1) foi parafraseada por negócio em R1. Isso mostra que as categorias linguísticas funcionam simultaneamente.

Marcuschi (1992, 2006b) descreveu cuidadosamente esse processo, mostrando que o falante (i) repete-se a si mesmo ou ao seu interlocutor, com larga predominância de autorepetições sobre as heterorepetições; (ii) situa as repetições em contiguidade linear ou as separa por meio de outros tópicos; (iii) repete sintagmas, com larga preferência pela repetição de sintagmas nominais e sintagmas verbais.

O mesmo Marcuschi (2006b:232-254) destaca as diversas funções da repetição: (1) obtenção da coesividade textual; (2) facilitação da compreensão; (3) organização tópica, pois através da repetição podemos introduzir e reintroduzir um tópico, delimitá-lo, mantê-lo; (4) condução do argumento discursivo. Para outras funções, ver Castilho (1998a:74-75, 2000).

A paráfrase é outro processo constitutivo do texto, consistindo na recorrência de conteúdos. Mas esse termo remete a diversas realidades, assumindo importância até mesmo na argumentação sintática.

Fuchs (1982:49-50) assim definiu a paráfrase: “Transformação progressiva do 'mesmo' (sentido idêntico) no 'outro' (sentido diferente). Para redizer a 'mesma coisa' acaba-se por dizer 'outra coisa', no termo de um processo contínuo de deformações negligenciáveis, imperceptíveis."

O paradoxo da paráfrase está nisto: é uma repetição de conteúdos que, precisamente por terem sido repetidos, acrescentaram-se semanticamente e, nesse sentido, mudaram. Não é preciso dizer mais nada para mostrar a importância da paráfrase na manutenção da conversação e na criação do texto. Nem para destacar a importância do estudo da língua como um sistema complexo. Nessa perspectiva, as categorias não são opositivas, antes integrativas, ocorrendo simultaneamente.

Vejamos este exemplo: 
Exemplo (4), retirado de Hilgert 2006:290)

\begin{tabular}{|c|c|}
\hline$M$ & então a minha de onze anos ... ela supervisiona o trabalho dos cinco ... \\
\hline $\begin{array}{c}\text { então ela vê se as gavetas estão em ordem ... se o::material escolar já foi re/ } \\
\text { arrumado para o dia seguinte ... se nenhum::fez:::arte demais no banheiro ... } \\
\text { porque às vezes ... estão tomando banho e ficam jogando água pela janela }\end{array}$ \\
\hline $\mathrm{P}$ & quer dizer ... é supervisora nata \\
\hline
\end{tabular}

$M=$ matriz. $P=$ segmento parafraseado

Como se vê no exemplo (4), a paráfrase "tece a macroestrutura de um tópico conversacional, na medida em que mantém a centração tópica” (Hilgert, 2006:284).

São muitas as funções da paráfrase no tratamento discursivo do tópico: (1) expansão $v s$. redução, (2) determinação $v s$. indeterminação, (3) ênfase $v s$. atenuação etc. Não examinarei estas questões aqui.

\section{Descontinuação do quadro tópico: parentetização, digressão}

A construção do quadro tópico alterna-se com sua descontinuação, quando o deixamos de lado por alguns momentos, nos segmentos parentéticos, ou mesmo encaixando um tópico novo dentro do quadro, nas digressões. As duas estratégias ilustram o fenômeno da desdiscursivização, em que propriedades discursivas são desativadas.

Os segmentos parentéticos se constituem de pequenos esclarecimentos, comentários, perguntas, contendo observações rápidas ao tópico em desenvolvimento, que não chegam a comprometer a centração tópica, segundo Jubran (1996a, 2006b):

Exemplo (5), Projeto NURC EF SP 405

aqui nós só vamos ... fazer uma leitura em nivel PRE-iconográfico nós vamos reconhecer as formas ... então que tipo de formas que nós vamos reconhecer? ... nós vamos reconhecer bisontes ... ((vozes)) ... bisonte é o bisavô ... do touro ... tem o touro o búfalo:: e o bisonte MAIS lá em cima ainda ... nós vamos reconhecer ahn::cavalos ... nós vamos reconhecer veados ... sem qualquer (em nível) conotativoaí ... e algumas vezes MUIto poucas ... alguma figura humana ... aí parte ... de estatuária que a gente vai reconhecer a figura humana mas é muito raro ... neste período ...

Os trechos parentéticos do exemplo 5 foram negritados. Jubran (1996a:415) identificou as seguintes marcas formais dos parênteses: (1) pausa inicial e final, (2) entoação descendente no final, em contraste com a ascendente na retomada tópica, (3) incompletude sintática do enunciado anterior ao parêntese, (4) marcas de reintrodução tópica, como agora, porque, entre outros. 
Para uma análise mais fina dos parênteses, ver Jubran (2006b).

$\mathrm{Na}$ digressão aprofundamos o processo de descontinuação tópica, inserindo um tópico desviante, como em

Exemplo (6), Projeto NURC D2 SP 360

L1 - a outra de nove quer ser bailarina

L2 - ahn

lw

L1- ela vive dançando ([risos])

1

L2 - dançan/([risos])

L1 - é ela vive dançando a Laura a:: Estela a Laura não se definiu tenho impressão 1

$\mathrm{L} 2-(\ldots)$

L1 - de que ela vai ser PROmotora ...

L2 - ah

L1 - que ela vive acusando é aquela que ...

1

L2 - é aquela

L1 - toma conta do pessoal ([risos]) oh ... agora ah::- nossa! foi além do que eu ... imaginava ... o horário (...) não ... por causa das crianças na escola - ([risos]) agora a Estela vive dançando ... e ela quer ser bailarina ...

Fica bastante claro que no exemplo (6) o tópico "profissões futuras das filhas" foi interrompido por uma observação sobre o horário. Esse tópico desviante passa a ocupar longamente a atenção das locutoras, na continuação da entrevista, até que se retome o tópico das profissões. Isso mostra uma vez mais que as desativações são seguidas pelas ativações, qualquer que seja o sistema sob análise.

Uma série de marcas formais destaca a digressão do quadro tópico: (1) muda-se o tempo verbal, de presente para pretérito, (2) pausas separam a digressão do texto maior, (3) marcadores discursivos podem assinalar que se entrou por um desvio do assunto.

\section{Conexão textual}

Ao identificar as unidades tópicas, nota-se que elas podem vir ligadas por conectivos que ultrapassam obviamente os limites da sentença.

No Quadro 2, unidades 3 e 8, viu-se que as expressões mas ... e ... interligam unidades tópicas. Nesse uso, elas não funcionam como conjunções sentenciais, pois o escopo destes operadores tem uma extensão menor. Por assim dizer, conjunções sintáticas vão de escopinho, enquanto que conectores textuais vão de escopão. Os efeitos de sentido vão acompanhar a extensão do escopo. O mas conectivo textual da unidade 3, por exemplo, não é contrajuntivo. 
De todo modo, há certos requisitos para que os itens lexicais atuem como conectores textuais. Eles devem ser expressões fóricas, pois devem retomar o que se disse e anunciar o que se segue. Uma expressão referencial não reúne as condições para atuar como conectivo. Veja o seguinte exemplo, que transcrevi de forma a pôr em relevo os conectivos textuais, negritando-os:

\section{Exemplo (8) - Conectivos textuais no D2 REC 05}

Ll - não não não é questão disso não

\section{mas}

realmente a cadeia de supermercados aqui é de de de de de Recife provavelmente é superior a qualquer uma do país ... isso vocês podem julgar lá vendo ...

\section{mas}

não não não é propaganda não é coisa nenhuma

\section{agora}

o que eu acho é o seguinte ... é que nós temos

L2 - () problema de saneamento isso é seríssimo

L1 - nós temos aquelas aquelas desvantagens de qualquer civilização colocada no trópico ...

\section{mas}

como eu dizia há pouco a cada:: ... vantagem a desvantagem corresponde a uma vantagem também ... aqui tem brisa marinha ...

\section{então}

nós temos os ventos alísios que vêm aqui éh: ... soprando aqui perto soprando temos a brisa terral de manhãzinha cedo ... o que faz com que a polvição seja um bem mais difícil

\section{L2 -agora}

Recife tem um problema muito sério é porque em sendo Recife a a maior cidade do Nordeste ... há uma convergência

L1 não Recife é a maior cidade do mundo ... porque é aqui que o Capibaribe se encontra com o Beberibe pra formar o Oceano Atlântico

1

L2 - eu concordo com você

$\mathrm{Ll}-((\mathrm{riu}))$

L2 - mas então

há esse problema

\section{então}

a coisa se agrava

Fixando a atenção em agora, Risso (1993:34-35) identifica as seguintes propriedades nesse conectivo textual:

(1) "O conectivo não é desencadeado pela fórmula interrogativa 'quando?.." De fato, seria impossível interpretar agora ... Recife .. como uma resposta à pergunta quando? Logo, não se trata de um adjunto adverbial de tempo. 
(2) O conectivo "não é passível de enquadrar-se como foco de orações clivadas", o que faria dessa forma um constituinte da sentença. Não é possível aceitar (8a) "é agora que Recife tem um problema muito sério.

que nos levaria a uma paráfrase incongruente com (8).

(3) As propriedades prosódicas do agora de (8) o apartam do adjunto adverbial de tempo: enquanto aquele é separado por pausas e recebe uma entoação descendente, este é dito emparelhadamente com a sentença.

(4) Seja como conectivo textual, seja como adjunto adverbial de tempo, agora preserva sua propriedade semântica de dêixis temporal. No primeiro caso, ele marca um momento do tempo discursivo, dada pela "relação de sucessividade entre tópicos ou segmentos de tópicos". No segundo, um momento do tempo cronológico, exterior ao tempo do texto.

Ocorrências como essas deram origem a um conjunto de pesquisas, em que se indagou a relação entre os conectivos textuais e as conjunções sentenciais. O primeiro estudo do PB neste particular foi preparado por Dias de Moraes (1987).

Nessas pesquisas, frequentemente as conjunções sentenciais foram consideradas como resultado da gramaticalização dos conectivos textuais. Ou seja, supõe-se que as conjunções venham ao mundo primeiramente como conectivos textuais, e depois se metem adentro das sentenças, transformando-se em conjunções. Sempre o insuficiente entendimento da língua como uma linha! Por que não admitir que tudo isso ocorra ao mesmo tempo (2)?

\section{ESTRATÉGIAS CONVERSACIONAIS E PROCESSOS DE CRIACÃ̃O LINGUIISTICA}

Podemos buscar, agora, uma generalização com base no exame das estratégias conversacionais. Para seguir adiante, precisaremos inicialmente selecionar uma orientação espistemológica. Vamos de teoria dos sistemas complexos - e aqui a ausência do Marcuschi, filósofo de formação, nos fará uma falta ainda maior.

Para trazer essa epistemologia para o campo da Linguística, propus a Abordagem multissistêmica, que venho elaborando desde 1998, como uma proposta de exploração da teoria dos sistemas complexos no estudo da constituição de uma língua natural: Castilho (1998 a, b, 2002 a, b, 2007, 2009 a, b, c, 2010 a, c, 2016, Castilho et al. 2016 no prelo), Castilho e Moraes de Castilho (2011). Algumas teses de doutorado foram defendidas com base na abordagem multissistêmica: Modolo (2004), Kewitz (2007), Simões (2007), Laura (2013), Kobashi (2013), Braga (2016). Na mesma perspectiva teórica, encontram-se em andamento as teses de Marcel Caldeira, sobre a diacronia da concordância em verbos não predicativos equativos e existenciais, Flávia Orci Fernandes, sobre a diacronia da concordância em sentenças relativas, e Janaína Olsen, sobre a diacronia da concordância do infinitivo pessoal. Em seu livro de Introdução à linguística, Bagno (2014:23-27) integra esta proposta entre outras teorias linguísticas. 
O entendimento das línguas naturais como um sistema complexo se fundamenta nos seguintes postulados:

- Postulado 1: A língua é um conjunto de quatro sistemas, organizados por categorias próprias, a saber, o Léxico, a Semântica, a Gramática, o Discurso. Esses sistemas funcionam autonomamente, não se postulando sistemas centrais nem sistemas periféricos.

- Postulado 2: As categorias que configuram esses sistemas são problemáticas, no sentido de não opositivas. Elas são vagas, indeterminadas, ambíguas, polissêmicas, problemáticas, não exclusivas, polifuncionais, operando simultaneamente num mesmo recorte de língua.

- Postulado 3: Os sistemas linguísticos são administrados por um dispositivo sociocognitivo, baseado nas estratégias conversacionais. A ação desse dispositivo consta de três movimentos mentais: ativação, desativação e reativação das categorias que organizam os sistemas numa forma autoregulada. Decorrem desses movimentos os Princípios de projeção, recursão e elipse. Os processos de criação linguística assentam nesses princípios: a lexicalização, a semanticização, a gramaticalização e a discursivização.

O estudo da oralidade, portanto, abre caminho à formulação de princípios linguísticos, suficientemente fortes para investigar os processos de criação linguística. Este foi um resultado inesperado das pesquisas sobre a oralidade.

Vejamos como o "dispositivo sociocognitivo" atua nos quatro sistemas linguísticos.

\section{Sistema do discurso}

Proponho que o dispositivo sociocognitivo opera da seguinte maneira no sistema do Discurso:

(i) Ativação de categorias: criação e manutenção dos turnos na conversação, construção da unidade tópica no texto.

(ii) Reativação de categorias: sistema de correção na conversação, repetição e paráfrase no texto.

(iii) Desativação de categorias: despreferências na conversação, parentetização e digressão no texto.

\section{Sistema da gramática}

Exercício semelhante se pode fazer se observarmos a constituição da sentença no sistema da Gramática, particularmente na Sintaxe, em que teríamos: 
(i) Ativação: projeção dos argumentos sentenciais.

(ii) Reativação: repetição e redobramento de categorias.

(iii) Desativação: elipse de constituintes.

Ainda está por ser examinado o impacto das pesquisas sobre o português brasileiro falado no desenvolvimento de novos temas na pesquisa gramatical brasileira.

Vou aqui dar uma pequena contribuição a esse campo, lembrando que Marcuschi e eu mesmo tínhamos suspeitado que havia outros campos a explorar em nossas análises sobre alternância de turnos e marcadores conversacionais. Saiu então meu artigo Da análise da conversação para a análise gramatical publicado em 1989, e do Marcuschi o artigo Análise da conversação e análise gramatical, publicado em 1991.

Reparei na ocasião que também o ensino da língua portuguesa poderia beneficiar-se da apropriação das pesquisas sobre a oralidade. Resultou daqui meu livrinho de 1998, A lingua falada e o ensino do português. Mas havia muitos argumentos a desenvolver nesse livrinho, desde que se encontrasse uma moldura epistemológica apropriada. Surgiu assim a Nova gramática do português brasileiro, que publiquei no ano de 2000. Embora intitulado "gramática", ele elabora análises lexicais, semânticas e discursivas.

\section{Sistema do léxico}

No sistema do Léxico, teremos, respectivamente:

- Ativação: criação das palavras.

- Reativação: relexicalização das palavras por derivação e composição.

- Desativação: deslexicalização, que é a morte das palavras.

\section{Sistema da semântica}

No sistema da Semântica, teremos:

(i) Ativação: criação dos sentidos, via representação das categorias cognitivas.

(ii) Reativação: ressemanticização, via metáfora e metonímia.

(iii) Desativação: dessemanticização, via desaparecimento de um campo semântico: Castilho (2010, cap. 2).

\section{DO MICROCOSMO CONVERSACIONAL À FORMULAÇ̃̃o DE PRINCÍPIOS LINGUIISTIICOS}

Numa simples conversação assenta todo o complexo edifício da linguagem. De fato, pode-se verificar que o dispositivo sociocognitivo ativação/reativação/ 
desativação de propriedades, postulado com base nas estratégias conversacionais, abre caminho à formulação dos Princípios gerais que ordenam os sistemas linguísticos das línguas naturais. Postularei, então, que os princípios gerais de Projeção, Recursão e Elipse assentam nesse dispositivo. Vejamos rapidamente como esses princípios operam numa língua como o PB. Antes disso, é preciso sublinhar que a Abordagem multissistêmica focaliza os processos de constituição das línguas naturais, com prioridade sobre a análise de seus produtos.

\section{Princípio de projeção}

O termo projeção deriva de projetar, e será aqui utilizado no seu sentido corrente de (i) "ato ou efeito de arremessar, jogar algo para algum lugar", (ii) "calcular antecipadamente uma situação futura", (iii) "perceber um objeto mental como algo espacial e sensivelmente objetivo".

O Princípio de projeção aplica-se a todos os sistemas linguísticos, embora seja mais conhecido como um princípio gramatical: Castilho (2012). Seus traços, entretanto, ultrapassam o sistema da gramatical, como demonstraremos a seguir.

\section{(1) Projeção lexical}

A Teoria dos espaços mentais explica como uma palavra projeta outra: Fauconnier (1984-1985). Essa teoria se ocupa, igualmente, do que estou chamando Projeção semântica.

\section{(2) Projeção gramatical}

Para construir as sentenças, usamos expressões predicadoras que arremessam seus traços lexicais sobre outras expressões, os argumentos sentenciais, atribuindo-lhes (i) casos e papéis temáticos, (ii) uma dada disposição no enunciado. A Gramática tradicional havia identificado em suas linhas gerais esses efeitos da projeção, denominando-os regência, concordância e colocação. A série escrita por Carlos Góis é exemplar a esse respeito: Góis (1931, 1932, 1933).

Para denominar uma das manifestações gramaticais desse princípio, por que a nomenclatura gramatical teria escolhido o termo transitividade, derivado de transitiuus, que vem do verbo de ação transire, "atravessar, passar, ir além”? Arrisco uma resposta: por trás dessa decisão se reconheceu uma das manifestações da categoria cognitiva de MOVIMENTO FICTÍCIO: Talmy (2000). Entendeu-se que a sentença representa uma sorte de percurso, em que um estado de coisas "passa" do agente para o paciente, explicação que obviamente só funciona para os verbos de ação. Em face desse entendimento, explicar a transitividade como a propriedade de passar da voz ativa para a voz passiva é restringir sua dimensão. 


\section{(3) Projeção semântica}

Para construir os sentidos, movimentamos traços semânticos pelo enunciado, via predicação, metonímia e metáfora. Outras categorias semânticas assentam igualmente no MOVIMENTO de traços, quando atribuímos sentidos (= referenciação) ou propriedades (= predicação), quando retomamos esses sentidos (= foricidade), ou quando os ampliamos (= inferência, pressuposição), e assim por diante.

A Semântica Cognitiva andou arando os campos férteis da projeção, mesmo sem utilizar consistentemente esse termo. Assim, Fauconnier (1984-1985, 1996) sustentou que as estruturas gramaticais fornecem indícios sobre a construção dos espaços mentais, definíveis inicialmente como um conjunto de percepções evocadas diretamente por uma expressão linguística ou pelas situações do discurso, denominadas em seu texto "evocações pragmáticas". Assim, uma palavra como escritor, do domínio da expressão, evoca logo a noção de livros, do domínio da evocação pragmaticamente sustentada, o que dá lugar a sentenças do tipo:

Exemplo (9)

Em seguida sou eu quem provoca um baque surdo no corredor, ao derrubar quatro Camões da prateleira alta. Chico Buarque - $O$ irmão alemão. São Paulo: Companhia das Letras, 2014, p. 32.

isto é,

(9a) ... derrubei quatro livros escritos por Camões.

Entre a expressão - que funciona como gatilho da evocação - e o espaço mental evocado, situa-se nosso conhecimento de mundo, que opera, então, como uma espécie de "conector pragmático". As observações de Fauconnier mostram que pensamentos altamente elaborados no domínio das ciências, das artes e das literaturas, tanto quanto a compreensão elementar da significação das sentenças produzidas nas situações do dia-a-dia, são regidas pela projeção (= Ing mapping) e pela combinação de espaços mentais. Numa leitura pessoal dessa teoria, direi que ele identificou a atuação do princípio de projeção no sistema da Semântica, de que resulta a criação dos sentidos.

\section{(4) Projeção discursiva}

Como vimos na anteriormente, durante uma conversação prevemos nosso momento de entrada na conversação e lançamos nosso turno à roda, configurando a Projeção discursiva. Também aqui os pesquisadores da Análise da Conversação abriram caminho a uma generalização a que denominei anteriormente "princípio pragmático de projeção": Castilho (1998a). 


\section{PRINCÍPIO DE RECURSÃO}

O Princípio de recursão, ou de recursividade, é a possibilidade de "aplicar uma regra repetidas vezes na construção das frases”: Xavier; Mateus (1992, s. v. recursividade).

O termo tem sido frequentemente usado para retratar a possibilidade de produzir infinitamente expressões encaixadas umas noutras, como é o caso das sentenças adjetivas e dos sintagmas preposicionais, entre outros. Essa percepção tem o defeito de limitar o Princípio de recursão à Gramática de uma língua, e mesmo assim, apenas às construções encaixadas.

Se reconhecermos sua extensão maior, veremos que ele capta as situações linguísticas em que retomamos o que já foi dito, ou escrito, fazendo recorrer categorias gramaticais (= segmentos de palavras, palavras, sintagmas, sentenças), categorias semânticas (sentidos parafraseados, sentidos que retornam à nossa mente, por foricidade) e categorias discursivas (unidades discursivas parafrásticas).

Sem dúvida as categorias gramaticais têm sido as mais pesquisadas do ponto de vista da recursão.

O Princípio de recursão descarta a visão unidirecional das línguas naturais, bastante tematizada pelos pesquisadores da gramaticalização. A sucessão de fases de uma mesma expressão é uma ilusão de ótica. A língua retorna sempre sobre si mesma, refazendo interminavelmente seus caminhos, numa espécie de entropia.

\section{(1) Recursão lexical}

O tautossilabismo, ou seja, a recorrência da mesma sílaba, dá surgimento a palavras que indicam relação de parentesco, como papai, mamãe, titio, vovô, derivadas de pai, mãe, tio, vô (de avô). Outras evocam a sensualidade (lepo-lepo, nheco-nheco, pega-pega, treme-treme, rala-rala), a agitação do dia-a-dia (lufa-lufa, empurra-empurra), a conversa sem importância (lero-lero, blá-blá-blá), os apelidos (Juju, Mimi, Dudu, Fafá, Zezé), e assim por diante (bangue-bangue, pisca-pisca, bilu-bilu, cri-cri, teco-teco, reco-reco, quero-quero, xique-xique, pingue-pongue. Exemplos de Jean Lauand, Lingua Portuguesa 104: junho de 2014:14-15.

A homonímia resulta igualmente da recursão lexical. Segundo Ilari (2002:103), "palavras homônimas são aquelas que se pronunciam da mesma maneira, mas têm significados distintos e são percebidas como diferentes pelos falantes da língua”. Ele dá os seguintes exemplos: manga "fruta", "parte de certas peças de roupa que cobrem os braços"; banco "assento num jardim, numa igreja”, "casa de crédito" etc.

Recursão é, também, a repetição pura e simples de palavras. Na língua falada, a repetição das palavras é um dos processos de criação dos enunciados, seja no sistema gramatical (Castilho 1997c), seja no sistema discursivo. 


\section{(2) Recursão gramatical}

A quantidade de expressões gramaticais é imensa, quase incontável. Entretanto, a estrutura dessas expressões é sempre a mesma. Qualquer que seja sua extensão, repete-se o seguinte esquema:

Margem esquerda (Especificador) + Núcleo + Margem direita (Complementizador) $\mathrm{O}$ que distingue as unidades linguísticas é o material com que preenchemos esses lugares estruturais. A recursão gramatical capta essa capacidade das línguas de construir suas estruturas fazendo recorrer a mesma regra de estruturação.

No quadro a seguir, reúne as unidades linguísticas que ilustram esse princípio.

Quadro 3 - A recursão gramatical

\begin{tabular}{|c|c|c|c|}
\hline Unidade & Especificador & Núcleo & Complementador \\
\hline Sílaba & Consoante/semiconsoante & Vogal & Consoante/semiconsoante \\
\hline Palavra & Prefixo & Radical & Sufixo \\
\hline Sintagma & $\begin{array}{c}\text { Artigo/pronome }- \text { V } \\
\text { auxiliar/Adv }\end{array}$ & $\begin{array}{c}\text { N-PRO./V/Adj/ } \\
\text { Adv/Prep }\end{array}$ & $\begin{array}{c}\text { SP/Sadj/Sentença relativa/ } \\
\text { Sadv }\end{array}$ \\
\hline Sentença & Sujeito & Verbo & Complementos \\
\hline
\end{tabular}

Num rápido repertório, nota-se que recorrem:

- as flexões, na concordância

- os possessivos (esta é a sua camisa dele)

- as expressões de grau, no PB vernacular (mais maior, mais menor)

- as preposições (desde, diante, que provêm de $d e+e x+d e, d e+a n t e)$

- os pronomes (isso eu te falei pra você)

- as sentenças relativas copiadoras (a casa de que te falei dela foi vendida)

- os tempos compostos do verbo (vou ir amanhã, tem tido muitos problemas)

- a negação (você não vai de jeito nenhum)

- argumentos sentenciais (o menino ele chegou).

\section{(3) Recursão semântica}

Os sinônimos exemplificam a recursão semântica, mesmo tendo-se em conta que eles são "palavras de sentido próximo", ou seja, não dispõem de sentido igual: Ilari (2004:119). Traços semânticos recorrem nas palavras sinônimas, acompanhados de outros traços.

\section{(4) Recursão discursiva}

As unidades tópicas descritas em Castilho (1998) exemplificam o Princípio de recursão discursiva: 
Quadro 4 - a recursão discursiva

\begin{tabular}{|c|c|c|}
\hline Margem esquerda & Núcleo & Margem direita \\
\hline $\begin{array}{c}\text { Marcadores orientados } \\
\text { para o interlocutor }\end{array}$ & $\begin{array}{c}\text { Sentenças tematicamente } \\
\text { centradas }\end{array}$ & $\begin{array}{c}\text { Marcadores orientados } \\
\text { para o texto }\end{array}$ \\
\hline
\end{tabular}

Os processos de reformulação, como a repetição, a correção e a paráfrase, constituem modalidades de recursão do tópico discursivo, funcionando na estruturação dos textos: Castilho (2010 a:5. 2. 3. 2).

\section{PRINCÍPIO DE ELIPSE}

Em línguas como o PB, podemos omitir certos constituintes, sejam gramaticais, semânticos ou discursivos. Tais omissões foram denominadas na literatura corrente elipse, categorias vazias, anáfora zero. A elipse mostra que também significamos quando ficamos em silêncio.

Os primeiros gramáticos gregos notaram que ao omitir uma expressão estamos remetendo, por meio do silêncio, à expressão projetada para figurar naquele lugar do enunciado. A gramática gerativa viria a denominar de "anáfora vazia" esta retomada de uma expressão por meio do silêncio.

Nesta seção, interpretamos a elipse seja como um segmento recuperável, seja como um segmento perdido, em virtude de alterações gramaticais no enunciado.

\section{(1) Elipse lexical}

Sufixos lexicais podem ser elididos, dando origem às formas regressivas, tais como satisfa (por satisfação), proleta (por proletário), japa (por japonês), estranja (por estrangeiro) etc. Algumas dessas formas perderam seu impacto, e não são mais percebidas como regressivas, tais como alinhavo, honra, ataque, prova (respectivamente de alinhavão, honrar, atacar, provar): Elia (1953, s. v. regressivo).

\section{(2) Elipse gramatical}

No PB, podem omitir-se o núcleo de uma sílaba, como em ('ants), por antes, o morfema flexional da palavra, o verbo da sentença, o argumento do verbo, um sintagma ou toda uma sentença, substituídos nesse caso por prossintagmas e por prossentenças: Castilho $(2010: 15.2,10.2$. 1. 6, 6. 5. 4, 8. 4). 
A omissão de segmentos fonológicos de palavras foi bastante estudada pelos neogramáticos, que desenvolveram toda uma terminologia para categorizá-las: aférese, se a omissão afetou a primeira sílaba da palavra (como em Lat atonittu> Port tonto), sincope, se a omissão afetou algum segmento medial (como em Lat viride, dolore > Port verde, dor), apócope, se a omissão afetou algum segmento final (como em Lat dolore, amores Port dor, amor).

O Especificador sintagmático pode ser omitido, gerando diferentes interpretações semânticas: cf. livro, por o livro, meu livro. O mesmo pode ocorrer com o Complementador: cf. Aquele sujeito é um mala, por mala sem alça, "inútil”; $F a$ lou um montão, por um montão de asneiras.

Também o Especificador e o Complementador sentenciais podem ser elididos, criando-se sentenças de sujeito nulo e de argumento interno nulo.

A elipse do núcleo sintático pode ou não demandar a ocorrência de uma classe de substituição. No caso das construções de tópico organizadas por sintagma preposicional não se exige essa classe. $\mathrm{Na}$ elipse do substantivo, pronomes podem substituí-los. $\mathrm{Na}$ elipse do verbo, proformas os substituem.

\section{(3) Elipse semântica}

Também os sentidos das expressões podem ser omitidos, sendo então substituídos por outros sentidos, no caso da metáfora, da metonímia da especialização e da generalização do sentido.

Esse tipo de elipse ocasiona a mudança semântica da palavra "sobrevivente". Assim, por meio do sintagma nominal mala sem alça queremos referir algo inútil, de difícil manejo. Com a elipse do Complementador sem alça, organizamos sentenças do tipo Fulano é uma/um mala, para designar alguém inútil, de trato difícil. O mesmo ocorre em Falou um montão de asneiras $\rightarrow$ Falou um montão.

\section{(4) Elipse discursiva}

Através das digressões e dos parênteses, podemos omitir um tópico discursivo que vinha sendo elaborado: Castilho (2010:5. 2. 4).

\section{CONCLUSÕES}

Em suma, partindo do microcosmo das estratégias conversacionais podemos chegar ao macrocosmo dos princípios gerais que regem uma língua natural, passando por uma análise controlada de seus aspectos lexicais, gramaticais, semânticos e discursivos. 
O seguinte quadro capta os argumentos aqui oferecidos ao debate.

Quadro-resumo: das estratégias conversacionais para os princípios linguísticos

\begin{tabular}{|c|c|c|c|}
\hline $\begin{array}{c}\text { Dispositivo } \\
\text { sociocognitivo }\end{array}$ & Conversação & Texto/sentença & $\begin{array}{c}\text { Princípio } \\
\text { linguístico }\end{array}$ \\
\hline Ativação & Manutenção dos turnos & $\begin{array}{c}\text { Construção da unidade } \\
\text { tópica/da estrutura } \\
\text { argumental }\end{array}$ & Projeção \\
\hline Reativação & Sistema de correção & $\begin{array}{c}\text { Repetição e paraphrase da } \\
\text { unidade tópica/dos } \\
\text { argumentos sentenciais }\end{array}$ & Recursão \\
\hline Desativação & Despreferências & Parentetização e digressão & Elipse \\
\hline
\end{tabular}

Encerro esta fala relembrando uma conquista da Linguística brasileira: a elaboração de pesquisas realizadas sob a forma de projetos coletivos. Há muitos deles no Brasil, felizmente. Eles aceleraram nosso conhecimento, propiciando, ademais, a confluência de diferentes habilidades, por incluir sempre pesquisadores ligados a diferentes teorias linguísticas.

O passamento de Luiz Antonio Marcuschi não interromperá as pesquisas linguísticas desenvolvidas por alunos e professores das universidades de Pernambuco. Graças a lideranças como a de Valéria Gomes, Coordenadora da equipe pernambucana do Projeto para a história do português brasileiro e Presidente do Grupo de Estudos Linguísticos do Nordeste, novos temas passaram a ser desenvolvidos, movimentando uma ciência de tanta importância para a revelação da identidade dos brasileiros.

\section{REFERÊNCIAS BIBLIOGRÁFICAS}

ABAURRE, Maria Bernadete M. (Org.), 2013. Construção fonológica da palavra. Gramática do Português Culto Falado no Brasil, v. VII. São Paulo: Contexto.

ALVES, Ieda Maria; RODRIGUES, Ângela Cecília (Org.), 2015. Construção morfológica da palavra. Gramática do Português Culto Falado no Brasil, v. VI. São Paulo: Contexto.

BAGNO, Marcos, 2014. Lingua, linguagem, linguística. Pondo os pingos nos ii. São Paulo: Parábola.

BRAGA, Henrique Santos, 2016. Construções imperativas no português brasileiro: uma abordagem funcionalista-cognitivista. São Paulo: Universidade de São Paulo, tese de doutoramento. 
CASTILHO, Ataliba T. de (1984a). El proyecto de estudio coordinado de la norma culta. Formalismo y semanticismo en la sintaxis verbal. Em: Donald F. Solá (Ed 1984). Language in the Americas. Proceedings in the Ninth PILEI Symposium. Ithaca: Cornell University, p. 161-165.

CASTILHO, Ataliba T. de (Org.), 1989). Português culto falado no Brasil. Campinas: Editora da Universidade Estadual de Campinas.

CASTILHO, Ataliba T. de. 1989b. Para o estudo das unidades discursivas do português falado, in A. T. de Castilho (Org.), 1989, p. 249-280).

CASTILHO, Ataliba T. de. 1989d. Da análise da conversação para a análise gramatical. Estudos linguísticos 17:219-226, 1989.

CASTILHO, Ataliba T. de, 1997a. A gramaticalização. Estudos linguísticos e literários 19:25-63, 1997.

CASTILHO, Ataliba T. de (Org.), 1993. Gramática do português falado, v. III, As abordagens. Campinas: Editora da Unicamp/Fapesp; 3. ed., 2002.

CASTILHO, Ataliba T. de, 1997c. Para uma sintaxe da repetição. Língua falada e gramaticalização. Língua e literatura 22:293-332, 1997 (Universidade de São Paulo).

CASTILHO, Ataliba T. de, 1998a. A língua falada no ensino do português. São Paulo: Contexto; $5^{\text {a }}$ reimpressão, 2014.

CASTILHO, Ataliba T. de, 1998c. Langue parlée et processus grammaticaux, in M. Bilger; K. van den Eynde; F. Gadet (Eds. 1998) Analyse linguistique et approches de l'oral. Recueil d'études offert en hommage à Claire Blanche-Benveniste. Paris/Leuven: Peeters, p. 141-148.

CASTILHO, Ataliba T. de, 2000. A repetição como processo constitutivo da gramática do português falado, in José Antonio Samper Padilla y Magnolia Troya Déniz (Org.), 2000. Actas del XI Congreso de la Asociación de Linguística y Filología de la América Latina. Las Palmas: Universidad de Las Palmas de Gran Canaria, t. III, p. 2289-2298.

CASTILHO, Ataliba T. de, 2003a. Análise multissistêmica das preposições do eixo transversal no Português Brasileiro, in J. Ramos; M. Alckmim (Org.) (2007). Para a história do português brasileiro, v. V: Estudos sobre mudança linguística e história social. Belo Horizonte: Faculdade de Letras da Universidade Federal de Minas Gerais, p. 53-132.

CASTILHO, Ataliba T. de, 2007. Abordagem da língua como um sistema complexo. Contribuições para uma nova Linguística Histórica, in A. T. de Castilho; M. A. Torres Morais; R. E. V. Lopes; S. M. L. Cyrino (Org. 2007). Descrição, história e aquisição do português brasileiro. Homenagem a Mary A. Kato. Campinas: Pontes/Fapesp, p. 329-360.

CASTILHO, Ataliba T. de (Org.), 2009. História do português paulista. Série Estudos, v. 1. Campinas: Instituto de Estudos da Linguagem, Unicamp.

CASTILHO, Ataliba T. de, 2009a. An approach to language as a complex system. New issues in Historical Linguistics, in Vanderci Aguilera (Org.), 2009. Para a história do português brasileiro. v. VII: Vozes, veredas, voragens. Londrina: Editora da Universidade Estadual de Londrina, t. 1, p. 1-44. Republicado em A. T. de Castilho (Org.), 2009:119-136. 
CASTILHO, Ataliba T. de, 2009b. Para uma análise multissistêmica das preposições, in A. T. de Castilho (Org.), 2009:279-332.

CASTILHO, Ataliba T. de, 2009d. Análise multissistêmica da sentença matriz, in V. L. M. de Oliveira e Paiva; M. do Nascimento (Org.), 2009. Sistemas adaptativos complexos. Lingua (gem) e aprendizagem. Belo Horizonte: Faculdade de Letras da UFMG, p. 35-60.

CASTILHO, Ataliba T. de, 2009e. Análise multissistêmica das minissentença, in S. S. C Ribeiro; S. B. B. Costa; S. A. M. Cardoso (Org.) 2009: Miscelânea de estudos dedicados a Jacyra Motta. Salvador: Universidade Federal da Bahia, p. 61-82.

CASTILHO, Ataliba T. de, 2010 a. Nova gramática do português brasileiro. São Paulo: Contexto.

CASTILHO, Ataliba T. de, 2010b. Para uma abordagem cognitivista-funcionalista da gramaticalização. Em: Dermeval da Hora; Camilo Rosa Filho (Org.). Para a história do português brasileiro. 1. ed. João Pessoa: Ideia/Editora Universitária, 2010, v. VIII, p. 272-283.

CASTILHO, Ataliba T. de, 2012. Princípio de projeção. In: Adeilson Pinheiro Sedrins et al. (Org.), 2012). Por amor à linguística. Miscelânea de estudos linguísticos dedicados a Maria Denilda Moura. Maceió: Editora da Universidade Federal de Alagoas, p. 29-64.

CASTILHO, Ataliba T. de, 2016. Do microcosmo conversacional para a formulação dos princípios linguísticos comunicação ao XII Lusitanistentag, Aachen, 2016.

CASTILHO, Ataliba T. de; MORAES DE CASTILHO, Célia Maria. 2011. Perspectiva multissistêmica da concordância, in Maria Célia Lima-Hernandes; Manoel Mourivaldo Santiago Almeida (Org.), 2011). História do português paulista. Série Ensaios, v. 3. São Paulo, p. 111-132.

CASTILHO, Ataliba T. de; CALDEIRA, Marcel; MARONEZE, Bruno; MORAES DE CASTILHO, Célia Maria; BUIN, Edilaine; FERNANDES, Flávia Orci; OLSEN, Janaína. 2016. Diacronia da concordância. Em: A. T. de Castilho; Célia Regina dos Santos Lopes (edição no prelo) Mudança sintática funcionalista. v. 3 da História do Português Brasileiro, no prelo.

DIAS DE MORAES, Lygia Corrêa. 1987. Nexos de coordenação na fala urbana culta de São Paulo. São Paulo: USP, Tese de doutoramento.

ELIA, Sílvio et al. 1955 (1953). Dicionário gramatical. Português. Rio de Janeiro/Porto Alegre/São Paulo: Globo.

FAUCONNIER, Gilles. 1984. Espaces mentaux. Aspects de la construction du sens dans les langues naturelles. Paris: Les Éditions de Minuit. Tradução para para o inglês: Mental spaces. Cambridge: The MIT Press, 1985.

FUCHS, Catherine. 1982. La paraphrase. Paris: Presses Universitaires de France.

GÓIS, Carlos. (1931) 1943. Sintaxe de regência. Rio de Janeiro: Paulo de Azevedo \& Cia.

GÓIS, Carlos. (1932) 1940. Sintaxe de construção. Rio de Janeiro: Francisco Alves.

GÓIS, Carlos. (1932)1955. Sintaxe de concordância. Rio de Janeiro: Francisco Alves. 
GRICE, H, p. 1982. Lógica e conversação. Em M. Dascal (Org.) 1982:81-103. HILGERT, José Gaston. 1989. A paráfrase: um procedimento de constituição do diálogo. São Paulo: Universidade de São Paulo, Tese de doutoramento.

HILGERT, José Gaston, 2006. Parafraseamento. Em C. C. S. Jubran/I. G. V. Koch (Org.) 2006. Gramática do português culto falado no Brasil, v. I, Construção do texto falado. Campinas: Editora da Unicamp, p. 275-300.

ILARI, Rodolfo, 2001b. Introdução à semântica. Brincando com a gramática. São Paulo: Contexto, 5. ed.

ILARI, Rodolfo, 2002. Introdução ao estudo do léxico. Brincando com as palavras. São Paulo: Contexto.

ILARI, Rodolfo (Org.), 2014. Palavras de classe aberta. Gramática do Português Culto Falado no Brasil, v. III. São Paulo: Contexto.

ILARI, Rodolfo (Org.), 2015. Palavras de classe fechada. Gramática do Português Culto Falado no Brasil, v. IV. São Paulo: Contexto.

JUBRAN, Clélia Cândida Abreu (Org.), 2015. Construção do texto falado. Gramática do português culto falado no Brasil, v. I: São Paulo: Contexto. 2. ed. de Ingedore Koch e Clélia Cândida Abreu Jubran (Org.), 2006). Gramática do português culto falado no Brasil, v. 1, A construção do texto. Campinas: Editora da Universidade Estadual de Campinas.

KATO, Mary; NASCIMENTO, Milton do (Org.), 2015. Construção da sentença. Gramática do Português Culto Falado no Brasil, v. II: São Paulo: Contexto, segunda edição de Mary Kato e Milton do Nascimento (Org.), 2009). Gramática do português culto falado no Brasil, v. 3, a construção da sentença. Campinas: Editora da Universidade Estadual de Campinas.

KEWITZ, Verena. 2007. Gramaticalização e semanticização das preposições a e para no português brasileiro (séculos XIX a XX). São Paulo: Universidade de São Paulo, Tese de doutorado.

LAURA, Fábio Izaltino. 2013. Abordagem multissistêmica da marcação de tema no português paulista. Campinas: Universidade Estadual de Campinas, tese de doutoramento.

LEVINSON, Stephen, 1983. Principles of pragmatics. New York: Longman. Pragmática. Tradução de Luís Carlos Borges. São Paulo: Martins Fontes, 2007.

MARCUSCHI, Luiz Antonio, 1975. Linguagem e classes sociais. Introdução crítica à teoria dos códigos linguísticos de Basil Bernstein. Porto Alegre: Coedições da Universidade Federal do Rio Grande do Sul.

MARCUSCHI, Luiz Antonio, 1983-2009. Linguística do texto: o que é, como se faz. Recife: Universidade Federal de Pernambuco; 2. ed., Recife: Editora Universitária da UFPe, 2009.

MARCUSCHI, Luiz Antonio, 1986. Análise da conversação. São Paulo: Ática.

MARCUSCHI, Luiz Antonio, 1988-1991. Análise da conversação e análise gramatical. Boletim da Abralin 10:1991, 11-34. 
MARCUSCHI, Luiz Antonio, 1989. Marcadores conversacionais do português brasileiro. Em: A. T. de Castilho (Org.), 1989:281-321.

MARCUSCHI, Luiz Antonio, 1992. A repetição na lingua falada. Formas e funções. Recife: Universidade Federal de Pernambuco, Tese para concurso de Professor Titular. MARCUSCHI, Luiz Antonio, 1996. A repetição na língua falada como estratégia de formulação textual. Em: I. G. V. Koch (Org.), 1996:95-129.

MARCUSCHI, Luiz Antônio. 2001. Da fala para a escrita. Atividades de recontextualização. São Paulo: Cortez.

MARCUSCHI, Luiz Antônio. 2002. Gêneros textuais: definição e funcionalidade. Em: A. P. Dionísio; A. R. Machado; M. A. Bezerra (Org.), 2002). Gêneros textuais e ensino. Rio de Janeiro: Lucerna.

MARCUSCHI, Luiz Antônio. 2006 a. Hesitação. Em C. C. S. Jubran; I. G. V. Koch (Org.), 2006:48-70.

MARCUSCHI, Luiz Antônio. 2006b. Repetição. Em C. C. S. Jubran/I. G. V. Koch (Org.), 2006:219-254.

MARCUSCHI, Luiz Antônio; KOCH, Ingedore G. Villaça, 2006c. Referenciação. Em C. C. S. Jubran/I. G. V. Koch (Org.) 2006:381-399.

MÓDOLO, Marcelo, 2004. Gramaticalização das conjunções correlativas. São Paulo: Universidade de São Paulo, Tese de doutoramento.

NEVES, Maria Helena de Moura (Org.), 2016. Construção das orações complexas. Gramática do português culto falado no Brasil, v. V. São Paulo: Contexto.

RISSO, Mercedes Sanfelice. 1993. 'Agora ... o que eu acho é o seguinte’: um aspecto da articulação do discurso no português culto falado, in A. T. de Castilho (Org.), 1993:31$60)$.

SACKS, Harvey; SCHEGLOFF, Emmanuel; JEFFERSON, Gail. 1974. A symplest systematics for the organization of turn-taking for conversation. Language 50:696-735, 1974. Tradução para o português: Sistemática elementar para a organização da tomada de turnos para a conversa. Veredas. Revista de Estudos Linguísticos 7 (1), 2003:9-73. SIMÕES, José da Silva. 2007. Sintaticização, discursivização e semanticização das orações de gerúndio no Português Brasileiro. São Paulo: Universidade de São Paulo, tese de doutorado.

TALMY, Leonard. 2000. Toward a cognitive semantics. Cambridge: The MIT Press, 2 vols.

URBANO, Hudinilson. 1993. Marcadores conversacionais. In: D. Preti et al. (Org.), 1993:81-102.

URBANO, Hudinilson. 2006. Marcadores discursivos basicamente interacionais. In: C. C. S. Jubran; I. G. V. Koch (Org.) 2006:497-528.

XAVIER, Maria Francisca; MATEUS, Maria Helena. 1990-1992. Dicionário de termos linguísticos, 2 volumes. Lisboa: Edições Cosmos/Associação Portuguesa de Linguística/ Instituto de Linguística Teórica e Computacional. 